\title{
Plastic Deformation of Thin Plates Subjected to Quasi-Static and Dynamic Loadings
}

\author{
A. A.N. Aljawi* \\ King Abdulaziz University, College of Engineering, P.O. Box 80204, Jeddah 21589, Saudi Arabia
}

Received 1 February 2003; accepted 11 November 2003

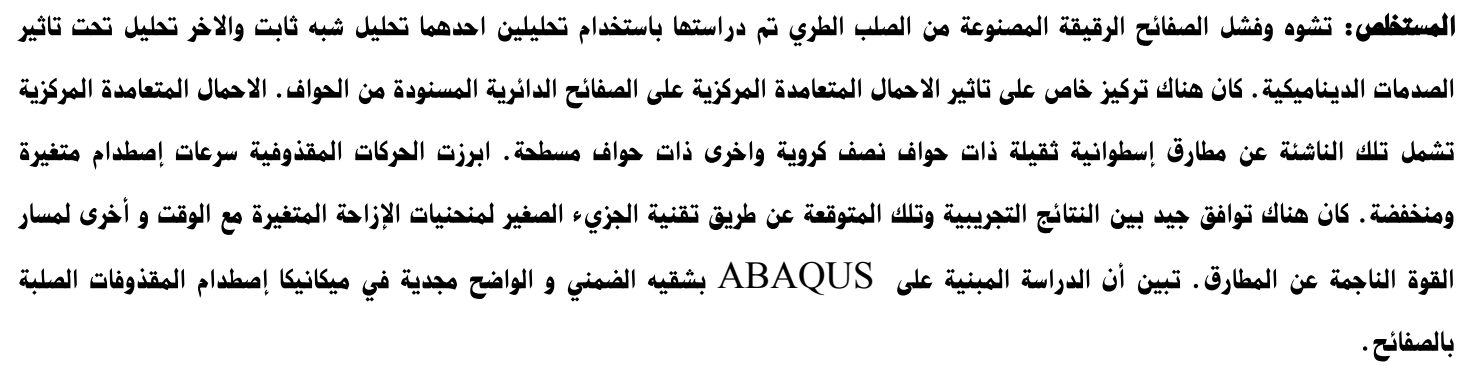

الهزرداه الهنتاهية: صفيحة رقيقة ، تقنية الجزيء الصغير ، التصادم التعاهدي ، شبه ثابت.

\begin{abstract}
Deformation and failure of thin plates of mild steel were studied under quasi-static and dynamic impact loadings. Particular emphasis was placed on responses of simply supported circular plates subjected to centric orthogonal loadings. The latter comprised loadings due to relatively massive rigid cylindrical strikers with a hemispherical-end as well as a flat-end. The projectile motions featured variable and low impact velocities. Generally, good agreement was found between experimental results and those predicted by finite-element techniques for displacement-time curves and for force histories of the striker. It was concluded that the ABAQUS-based study (both the implicit and the explicit versions) revealed beneficial insights into the impact mechanics of plates by rigid projectiles.
\end{abstract}

Keywords: Thin plate, FEM, Orthogonal impact, Quasi-static

\section{Introduction}

The study of projectile impact against targets or structures and structural components that undergo large plastic deformation have become main concerns for military and civilian applications (Goldsmith, 1972). Weights dropped, during maintenance or operation, on pipelines that transport dangerous materials, or on offshore platforms, and falling rocks in mountainous regions against shields or bridges, constitute examples of impact loading. These cases, as well as the design of shields themselves, against bullets or missiles, with much more complex behavior with reference to deformation modes, have been reported in the literature (Goldsmith, 1972; Davies, 1984a; Davies, 1984b; Reid, 1985; Jones, 1989; Zhao;2000).

Extensive theoretical and experimental research has been conducted in order to establish the basis for the design of selected structures (Awerbush, and Bonder, 1974; Beckman and Goldsmith, 1978; Corbett et al., 1997;

*Corresponding author E-mail:azhari_n@yahoo.com
Corbett and Reid, 1993; Corran et al., 1983; Jones and Shen, 1993; Langsen, and Larson, 1990; Shen, and Jones, 1993; Wen and Jones, 1993; Wen and Jones, 1994;). However, more experimental, theoretical as well as numerical research is still needed for the study of plastic collapse mechanisms of targets against projectiles.

Results were reported (Wen and Jones, 1993; Wen and Jones, 1994; Corbett and Reid, 1993) for a series of tests conducted on the quasi-static and dynamic local loading of circular plates resting on a ring support. A criterion for the inelastic rupture of ductile metal beams subjected to large dynamic loads was formulated and presented in (Jones and Shen, 1993). The results of experiments on pipelines with their ends fully clamped were presented in (Jones et al., 1992), whereas the same type of experimental investigation was reported in (Wen and Jones, 1993; Wen and Jones, 1994) for clamped circular plates loaded by transverse impact in both concentric and eccentric loading positions.

The finite element method (FEM) has been used extensively to simulate many applications in structural dynam- 
(a)
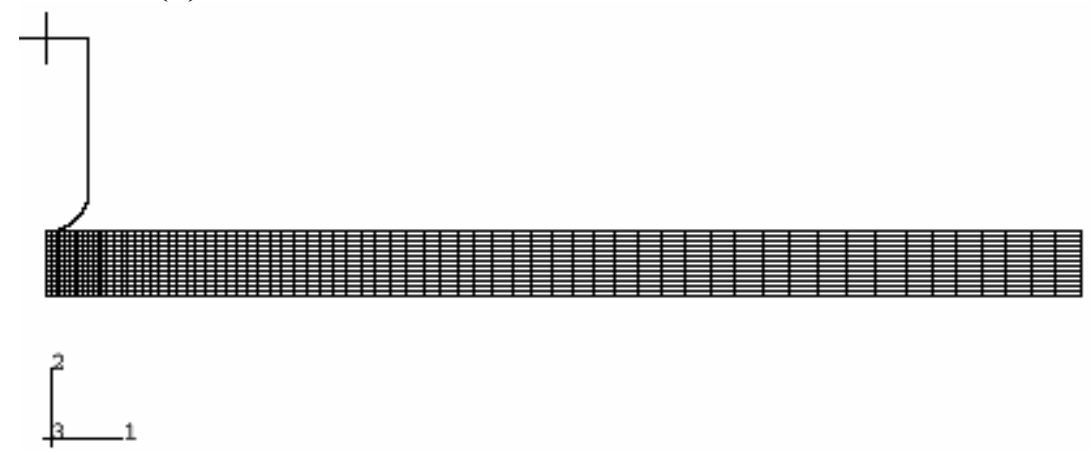

(b)

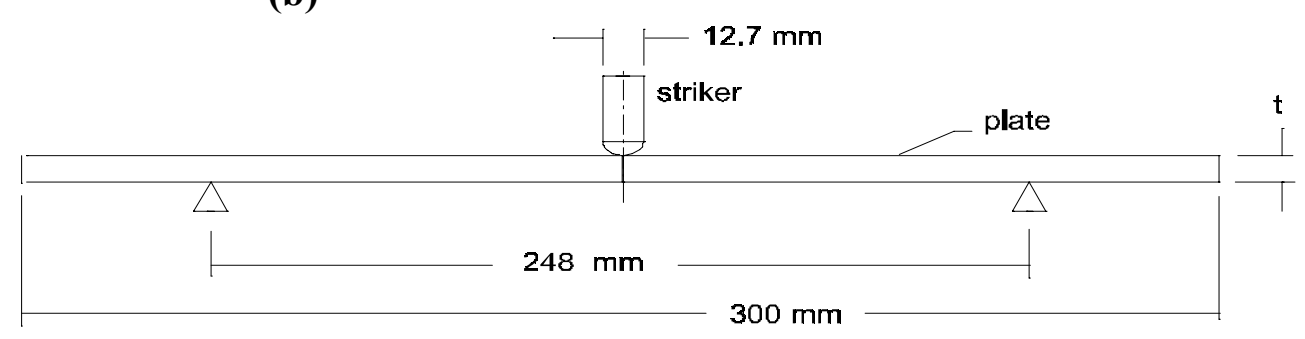

Figure 1. (a) Discretized 2-D Axi-symmetric model, (b) uniform simply supported plate and striker

ics (Aljawi, 1999; Bammann et al.,1993; HKS, 1998; Kormi et al., 1994; Kormi et al., 1993, Kormi and Webb, 1993; Sun et al., 2000). To this end, a number of algorithms were developed and implemented in FEM codes.

Preliminary studies were conducted by the present author on a system comprising a simply supported circular plate subjected to centric orthogonal loading, prior to the commencement of full-scale analysis, whereby responses from an FEM code were compared with published data and other experimental results (Shen, and Jones, 1993). Experimentally measured data (Wen and Jones, 1993; Wen and Jones, 1994; Corbett and Reid, 1993) were utilized for material properties in the FEM analysis. Encouraging results were obtained from these exploratory studies.

Following these preliminary analyses, the present study was initiated, where ABAQUS code (both the implicit and the explicit versions, Ver. 5.8) were employed to investigate the deformation of a ductile material under dynamic loading. The developed model was used to study the response of a circular mild steel plate subjected to centric loading. In an effort to limit the rather wide scope of the study, results of work concerning only two cases are presented here. These are quasi-static loading and loading with a relatively large mass, traveling at several low initial velocities. Both cases employed one striker with a hemispherical end and another striker with a flat face. The material properties used in the model were linear in the elastic range. They featured both linear and non-linear isotropic work-hardening characteristics in the plastic regime, being strain dependent for the dynamic case. A Cowper-Symonds type of power law (Symonds, 1965) was utilized to model the strain-rate dependence of the material. Comparisons of results obtained from both the implicit and the explicit versions of ABAQUS on the nonlinear quasi-static and dynamic cases were also reported.

\section{Quasi-Static Loading with Hemisperical Ended and Flat-Ended Strikers}

\subsection{Finite element model}

A two-dimensional axi-symmetric discretized model, shown in Figure 1a was considered. The model, which represents a circular plate of constant thickness $t$, loaded at its center, as shown in Figure 1b, consisted of four parts. These are a) the plate, b) the rigid surface representing the striker, c) the mass element associated with the striker, and d) a contact link that allows the energy to be transferred from the striker to the plate using the surface interaction. For the quasi-static case no mass was considered for the striker. Figure 1a shows half of the plate to be considered for mesh generation. A 4-noded axi-symmetric continuum element suitable for large deformation plasticity was used (CAX4) for this purpose, while the rigid body (striker) was modeled by 2-noded rigid elements (RAX2). The number of elements was 70 along the radius of the plate, while 14 elements were selected across the thickness. The particular number of elements across the radius and thickness were decided as dictated by the size of the mesh analysis.

The boundary condition imposed on the model constrained all nodes on the left half of the model (plane of symmetry in Figure 1a) to only move perpendicular to the model. Additional boundary conditions were needed that 
(a)
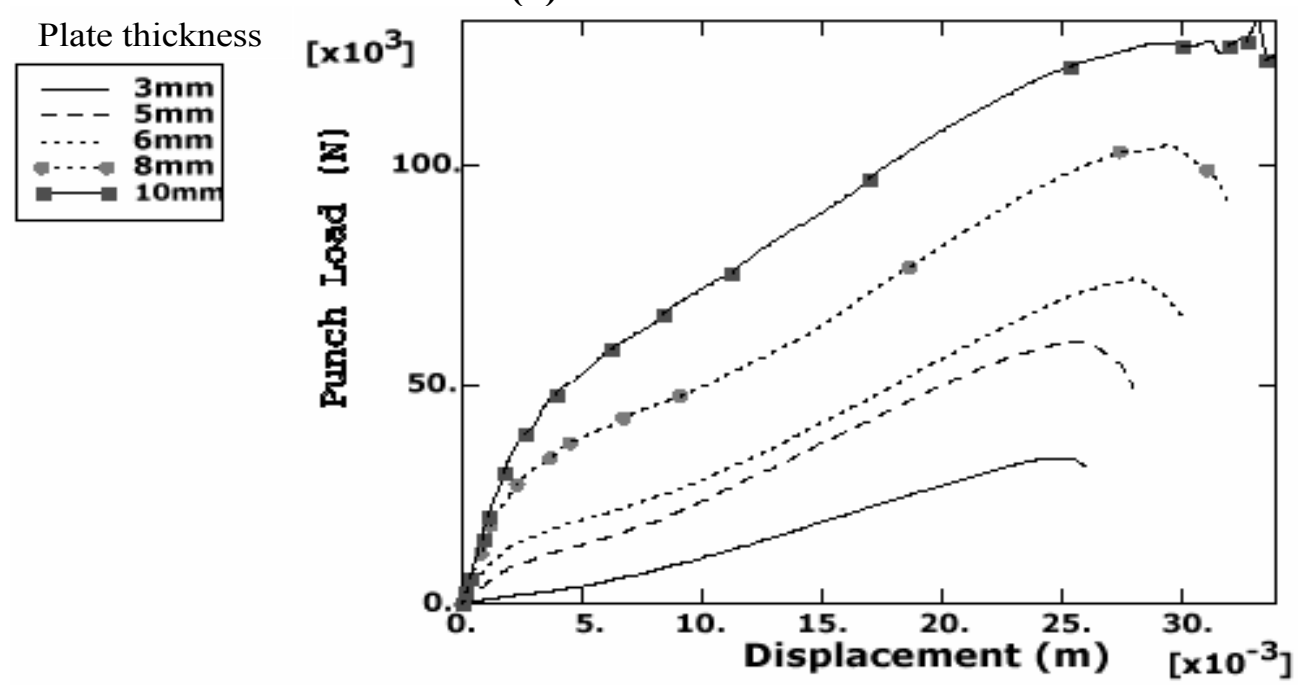

(b)

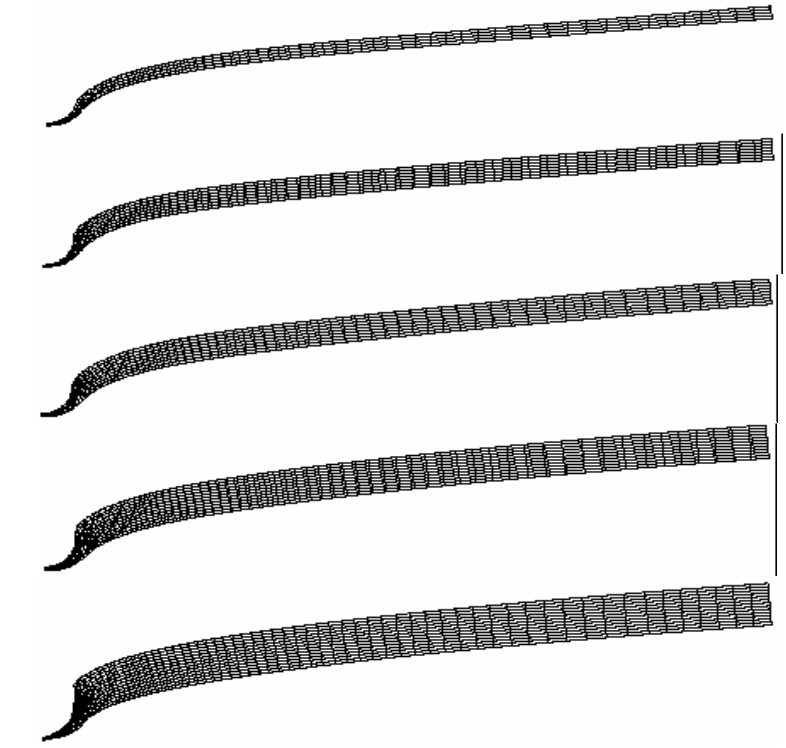

Figure 2. (a) Load-displacement curves for the hemisperical-faced striker,

(b) Thinned deformed shapes, for plate thickness of 3,5,6,8 and $10 \mathrm{~mm}$

are consistent with the model used. Additionally, constraints were imposed on the reference node located at the tip of the rigid body, the striker. It is to be noted that this rigid striker, shown in Figure 1, can carry the relatively large mass element of the striker, and generates the impact loading of the plate.

\subsection{Quasi-static loading of simply-supported steel plate}

In this investigation mild steel was used for modeling

Table 1. Material properties for quasi-static case (Corbett and Reid, 1993)

\begin{tabular}{|c|c|c|c|c|}
\hline $\begin{array}{l}\text { Plate thickness, } t \\
(\mathbf{m m})\end{array}$ & $\mathbf{D} / \mathbf{t}$ & $\begin{array}{c}\text { Yield Stress, } \sigma_{y} \\
\left(\mathbf{N} / \mathbf{m m}^{2}\right)\end{array}$ & $\begin{array}{c}\text { Ultimate Stress, } \sigma_{u} \\
\left(\mathbf{N} / \mathbf{m m}^{2}\right)\end{array}$ & $\begin{array}{c}\text { Young's modulus, } \\
\left(\mathrm{N} / \mathbf{m m}^{2}\right)\end{array}$ \\
\hline 3 & 100 & 273 & 440 & 228 \\
\hline 5 & 60 & 352 & 472 & 220 \\
\hline 6 & 50 & 305 & 446 & 235 \\
\hline 8 & 37.5 & 342 & 472 & 211 \\
\hline 10 & 30 & 251 & 490 & 230 \\
\hline
\end{tabular}


(a)

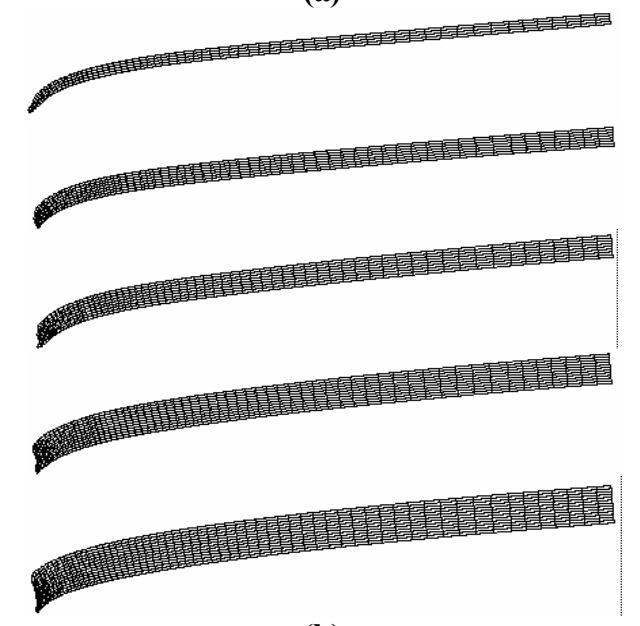

(b)

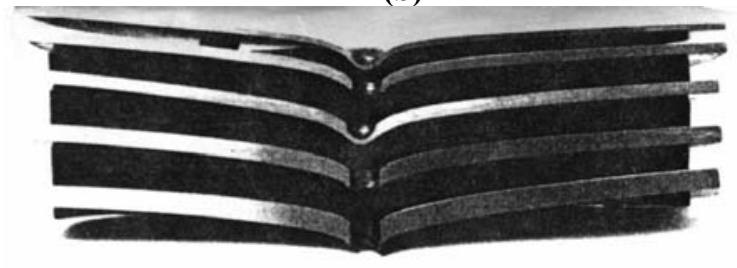

Figure 3. Perforated, (a) ABAQUS, and (b) experimental (Corbett and Reid, 1993), deformed shapes, for plate thickness of 3, 5, 6, 8 and $10 \mathrm{~mm}$

(a)

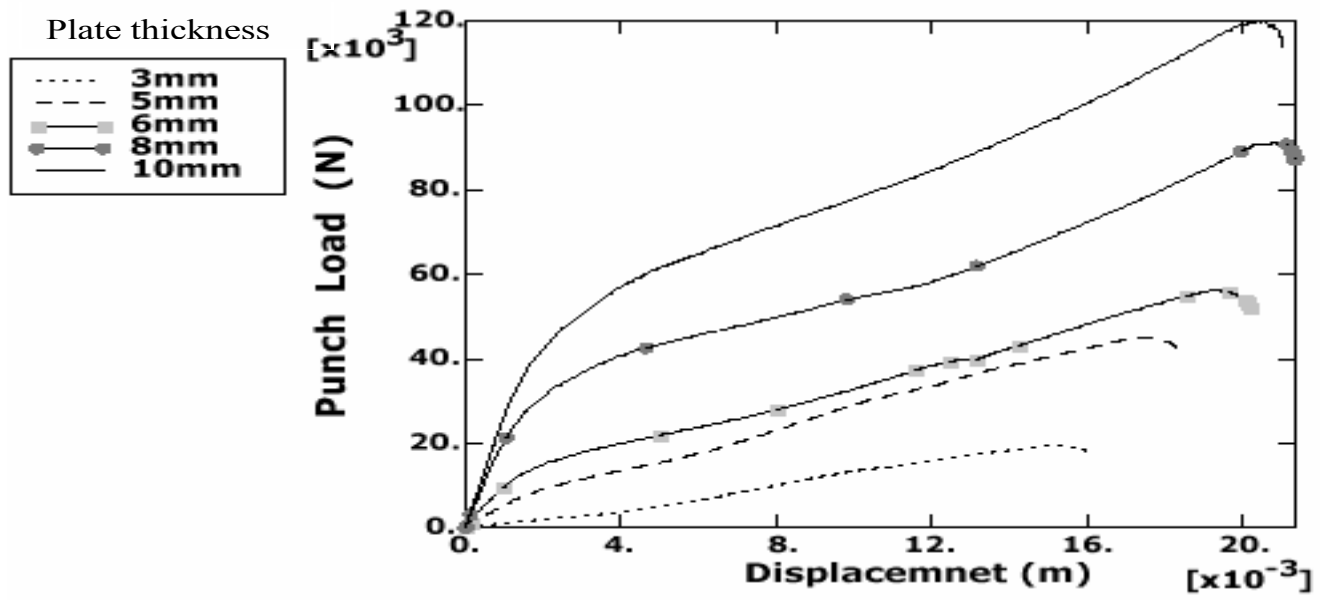

(b)

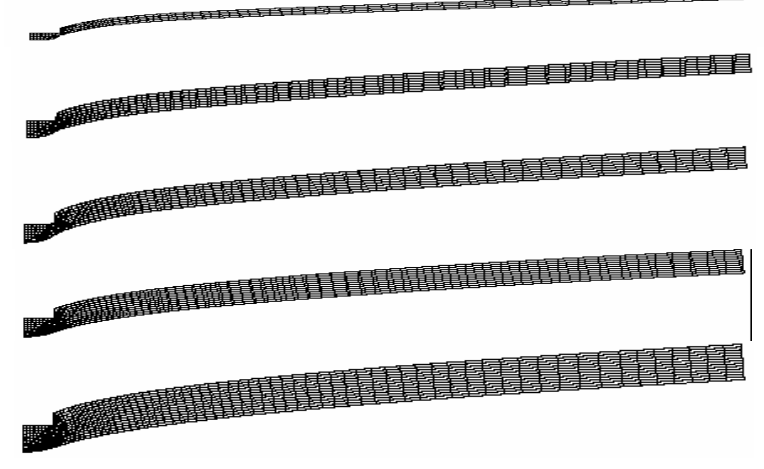

Figure 4. (a) Load-displacement curves for flat-end striker, (b) Deformed shapes, for plate thickness of $3,5,6,8$ and $10 \mathrm{~mm}$ 


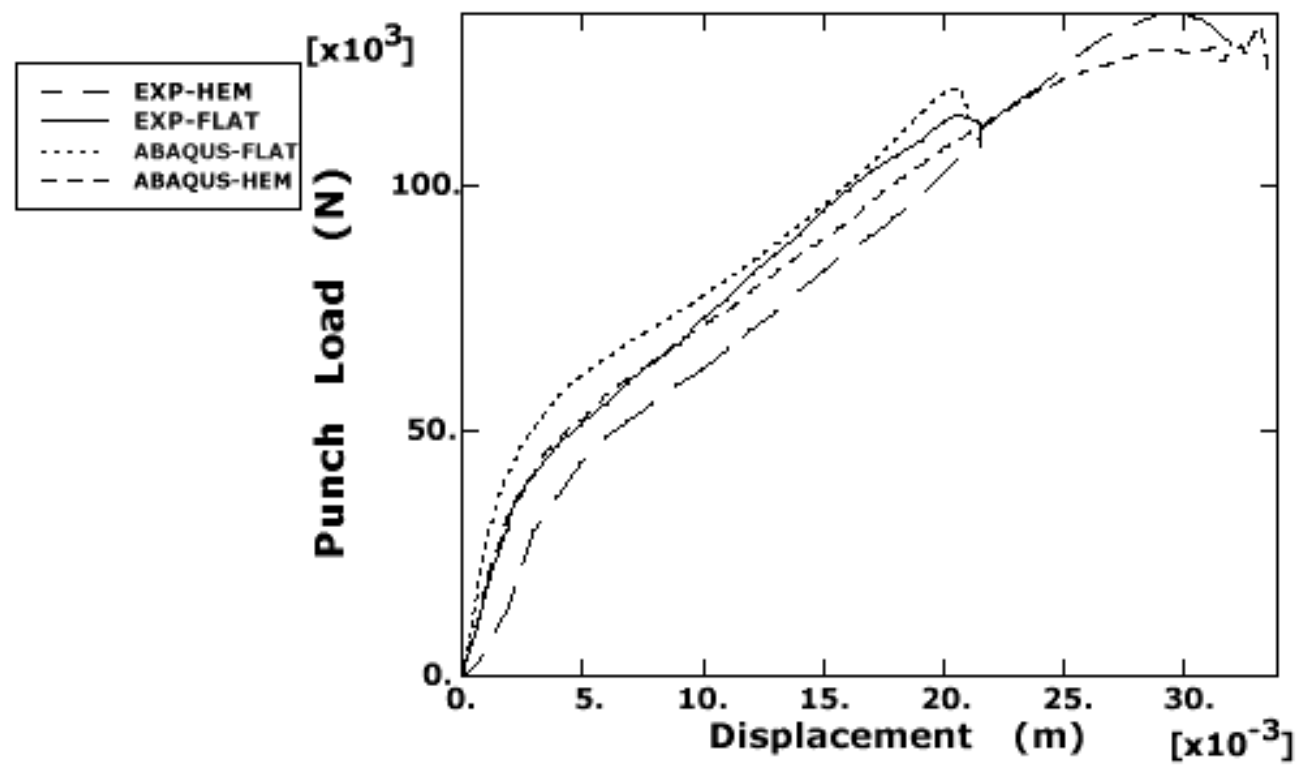

Figure 5. Comparison of the load-displacement curves between the experimental (Corbett and Reid, 1993) and ABAQUS analysis, for hemispherical and flat-ended striker of plate thickness $10 \mathrm{~mm}$

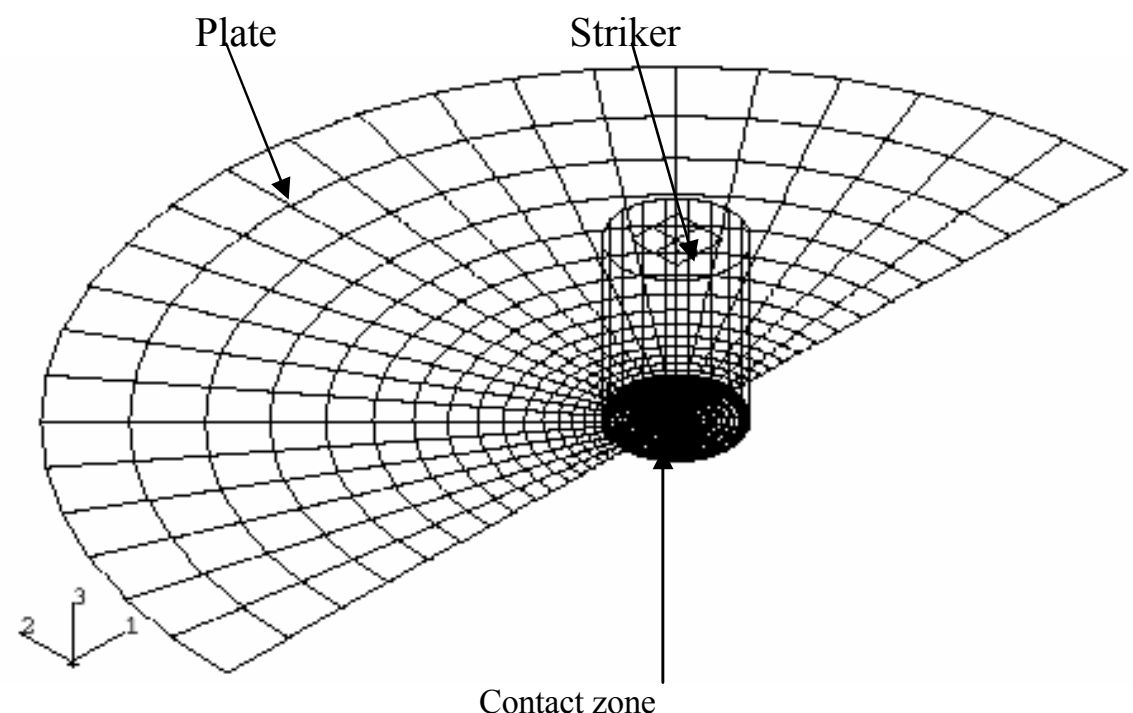

Figure 6. 3-Dimensional discretised model 
the plate of $300 \mathrm{~mm}$ in diameter, with $3,5,6,8$, and $10 \mathrm{~mm}$ in thickness $t$. Material properties and dimensions of the plate were taken from the experimental investigation reported in (Corbett and Reid, 1993 ) and given in Table 1. In this case, for all calculations, a piecewise elastic-plastic material model was used, with Poisson's ratio, $v=0.3$, and mass density, $p=7830 \mathrm{Kg} / \mathrm{m}^{3}$. Note that the plates are simply-supported at a diameter of $248 \mathrm{~mm}$, and loaded by a striker of $12.7 \mathrm{~mm}$ diameter (Figure 1b). The numerical simulation was carried out using the implicit standard version of ABAQUS 5.8. The computational comparison between both implicit and explicit algorithms will be discussed later.

Figure 2a shows the load-displacement curves when the hemispherical-end striker was used. As may be expected for quasi-static loading, the displacements were highly dependent on the diameter to thickness ratio $(D / t)$. The results shown in Figures 2(a) and 2(b) are qualitatively in good agreement with those reported in (Corbett and Reid, 1993 ). Figure 2(b) shows the sectioned profiles of the plate. Both figures indicate that the process involved continuous loading up of the punch load with displacement to perforation with remarkable thinning of the plate in the vicinity of the loaded area.

For a plate thickness of $3 \mathrm{~mm}$, Figures 2(a) and (b) show that a membrane-dominated mode of collapse took place. This indicated a continuous indentation of the plate leading to thinning. This effect became less pronounced as

Table 2. Material properties calculated from given measured values (Wen and Jones, 1993, 1994)

\begin{tabular}{ll}
\hline Material & Mild Steel \\
Specimen Identification * & STIII-26 \\
Yield Stress, ó $\left(\mathrm{N} / \mathrm{mm}^{2}\right)$ & 261.7 \\
Ultimate Stress, $\mathrm{o}_{\mathrm{u}}\left(\mathrm{N} / \mathrm{mm}^{2}\right)$ & 417.7 \\
$\mathrm{\triangle}_{\mathrm{f}}$ & 0.2769 \\
$\mathrm{~A}\left(\mathrm{~N} / \mathrm{mm}^{2}\right)$ & 541.5 \\
$\mathrm{~B}$ & 0.04 \\
$\mathrm{n}$ & 0.2259 \\
\hline
\end{tabular}

Table 3. Material isotropic work hardening characteristics (Wen and Jones, 1993)

\begin{tabular}{cc}
\hline $\begin{array}{c}\text { Effective Stress, } \bar{\sigma} \\
\left(\mathbf{N} / \mathbf{m m}^{2}\right)\end{array}$ & $\begin{array}{c}\text { Effective Strain, } \\
(\bar{\varepsilon} \mathbf{\%})\end{array}$ \\
\hline 261.7 & 9.9 \\
314.3 & 5.0 \\
347.3 & 10.0 \\
372.1 & 15.0 \\
392.3 & 20.0 \\
409.4 & 25.0 \\
424.4 & 30.0 \\
429.6 & 31.9 \\
437.0 & 35.0 \\
449.8 & 40.0 \\
460.9 & 45.0 \\
\hline
\end{tabular}

plate thickness increased. Consequently, a knee or change of slope can clearly be observed in Figure 2(a) for the 6,8 and $10 \mathrm{~mm}$ plates, indicating that bending-dominated plastic collapse mode took place. Once more, membrane effects also took place after plastic collapse. It is worth noting that the plate material under the area of the punch thinned to about $40-60 \%$ of the original plate thickness.

The explicit method in finite element analysis code enables a failure criterion to be incorporated into the solution procedure using the effective plastic strain, i.e. the plastic strain generated by the deviatoric stress state. This implies that failure is dependent on the Von-Mises stress and hence the failure occurrence is unaffected by the prevailing spherical stress state. The algorithm employed allows removal of elements from the mesh as a result of failure due to tearing and/or ripping of the structure. ABAQUS Explicit version allows for the automatic removal of elements from the mesh when the equivalent plastic strain exceeds the specified value. The material behaves elastically before initial yield is reached. Plastic strain then occurs following the conventional Von-Mises plasticity theory. If strain continues to increase, damage will remain, as long as the plastic strain is less than or equal to the offset plastic strain. However, if the plastic strain exceeds the offset plastic strain, damage will increase linearly, until the equivalent failure plastic strain is reached. At this strain level the material is considered to have failed. Figure 3(a), where all elements which have an equivalent plastic strain less than one have been removed, clearly indicates the continuous loading of the plate up to perforation, as well as the good agreement with the experimental findings as shown in Figure 3(b).

Load-displacement curves as well as sectioned profiles of the plates that are defined in Table 1, when loaded with the flat-end striker, are shown in Figures 4(a) and (b). It may be verified from inspection of Figures 4(a) and 4(b) that global deformation behavior of the plates are similar to the plates which are loaded with the hemispherical-end striker. What is observed is that, there is a continuous loading up of the punch load with increasing displacement, until perforation occurs; furthermore, the governing trend seems to be membrane-dominated mode of collapse for thin plates, and bending-dominated plastic collapse for thicker plates. However, load-displacement curves indicated that lower loads as well as lower deflections are required for perforation using a flat-end striker than their counterparts with the hemispherical-end striker.

Figure 5 shows the comparison of the load-displacement curves between the experimental results reported in (Corbett and Reid, 1993 ) and the current finite element model analysis, for both the hemispherical-ended and the flat-ended strikers when these are acting on a plate of thickness $10 \mathrm{~mm}$. It can be verified from Figure 5 that good agreement exists between the finite element predictions and the experimental findings. 


\section{Dynamic Loading of Clamped Steel Plates with Flat-End Striker}

An experimental investigation was reported in (Wen and Jones, 1993; Wen and Jones, 1994 ) for clamped circular plates loaded (in both concentric and eccentric loading positions) by cylindrical strikers of large masses with blunt ends, traveling at speeds up to $5.0 \mathrm{~m} / \mathrm{s}$. The case taken up in the present study was for a striker mass of 81 $\mathrm{kg}$, traveling at a speed of $4.43 \mathrm{~m} / \mathrm{s}$. The plate was $6 \mathrm{~mm}$ in thickness, $228.6 \mathrm{~mm}$ in diameter, clamped at a diameter of $152.4 \mathrm{~mm}$, and loaded by a flat-end striker $17.85 \mathrm{~mm}$ in diameter. In the current investigation only mild steel was used for modeling the plate.

\subsection{Material properties}

Material properties of the plate in the elastic range were taken as modulus of elasticity, $\mathrm{E}=2.01 \mathrm{~N} / \mathrm{mm}^{2}$, Poisson's ratio, $v=0.3$, and mass density of the material, $p=7830$ $\mathrm{Kg} / \mathrm{m}^{3}$ The material was considered to be linear in the elastic range, and the nonlinear stress-strain behavior in the plastic range obeyed an expression of type:

$$
\bar{\sigma}_{0}=A(B+\bar{\varepsilon})^{n}
$$

where values of $A, B$, and $n$ were based on experimental data (Wen and Jones, 1994), and are listed in Table 2. Thus, nonlinear work hardening characteristics of the material, based on the data given in Table 2, are presented in Table 3 that the first row of stresses correspond to the first row of strains, column by column, respectively.

Experimental findings (Wen and Jones, 1993; Wen and Jones, 1994) indicated that a plate structure that is subjected to an in-plane mass impact, even within the range of low velocity impacts, is highly sensitive to strain rate and inertia effects. It is both velocity and mass sensitive. The strain rate can be expressed using CowperSymonds (Symonds, 1965) empirical power law:

$$
\bar{\sigma}\left(\bar{\varepsilon}^{p}\right)=\sigma_{s}(\bar{\varepsilon})\left[1+\left(\frac{\dot{\bar{\varepsilon}}}{D}\right)^{\frac{1}{p}}\right]
$$

where, $\varepsilon p$, is the equivalent plastic strain, $\varepsilon_{\mathbf{S}}(\varepsilon p)$ is the quasi-staic yield stress, $\sigma(\varepsilon p)$ denotes the dynamic yield stress, $\varepsilon$ is thestrain rate, and $D$ and $P$ are material constants. For mild steel $D=40.5 \mathrm{~s}^{-1}$ and $p=5$. However, it was pointed out in (Symonds, 1965) that dynamic stress-strain curves become flatter with an increase in strain-rate, with reduced material strain hardening. Therefore, it was suggested that for mild steel, $D=1300 \mathrm{~s}^{-1}$ and $p=5$, or $D=300 \mathrm{~s}^{-}$ 1 and $p=2.5$ can also be used (Jones, 1983).

\subsection{Modeling}

Both 2-D and 3-D models were used for the dynamic loading conditions. The 2-D model was the same as in the quasi-static case, Figure 1. The 3-D, discretized model, shown in Figure 6, consisted of four parts. These are a) the plate, b) the rigid surface representing the striker, c) the mass element associated with the striker, and d) a contact link that allows the energy to be transferred from the striker to the plate. Figure 6 shows half of the symmetrical plate as discretized. Due to symmetry, only one-quarter of the plate is modeled. The half-plate model however, would enable comparisons for the case of eccentric impact loading.

The mesh shown in Figure 6 is symmetrical. It is uniform except in the impact zone, where the mesh is much denser than elsewhere. Three and four node shell elements (S3, S4R) were used in the discretized model, such that internal angles of the 4-node shell elements were in the range of $45^{\circ}-135^{\circ}$ to get better results.

The striker is visible in Figure 6 at the impact zone. The rigid striker was modeled as a cylindrical body with either a hemispherical-end, or a flat-end. For the hemisphericalend striker, the outermost segment of the end, containing the point of contact of the tip of the striker with the plate, had a radius of $8.925 \mathrm{~mm}$. The radius of the second circular arc defining the hemispherical tip was also $8.925 \mathrm{~mm}$. For the 3-D model, as shown in Figure 6, a line drawn parallel to the surface axis from the end of the second arc, and revolved 360 degrees about the central axis of the striker, generated the cylindrical body of the striker. An auxiliary node was attached to the tip of the striker. The utility of the auxiliary node was to represent the mass of the striker.

\subsection{Boundary conditions and constraints}

For the 3-D model, the boundary conditions imposed on the model were consistent with the existence of a diametrical plane of symmetry and a fully clamped outer circumference, Figure 6. Linear multi-point constraints were also imposed along the boundary lines joining the unrefined and refined meshes. The latter action allows the nodes on both sides of the line of symmetry to respond equally.

Additionally, constraints were imposed on the reference node located at the tip of the rigid body, the striker. It is to be noted that this rigid striker carried the relatively large mass element of the striker, and generated the impact loading on the plate.

\subsection{Loading}

For the 3-D model, impact loading was applied on the plate by energizing a $40.5 \mathrm{~kg}$ mass element, representing a total striker mass of $81 \mathrm{~kg}$ for the whole plate, with an initial velocity of $4.43 \mathrm{~m} / \mathrm{s}$. A mass of $81 \mathrm{~kg}$ was applied in the 2-D model. The motion of the striker was in a direction orthogonal to the plane of the plate. Gravity forces were ignored, since these were considered to be relatively 


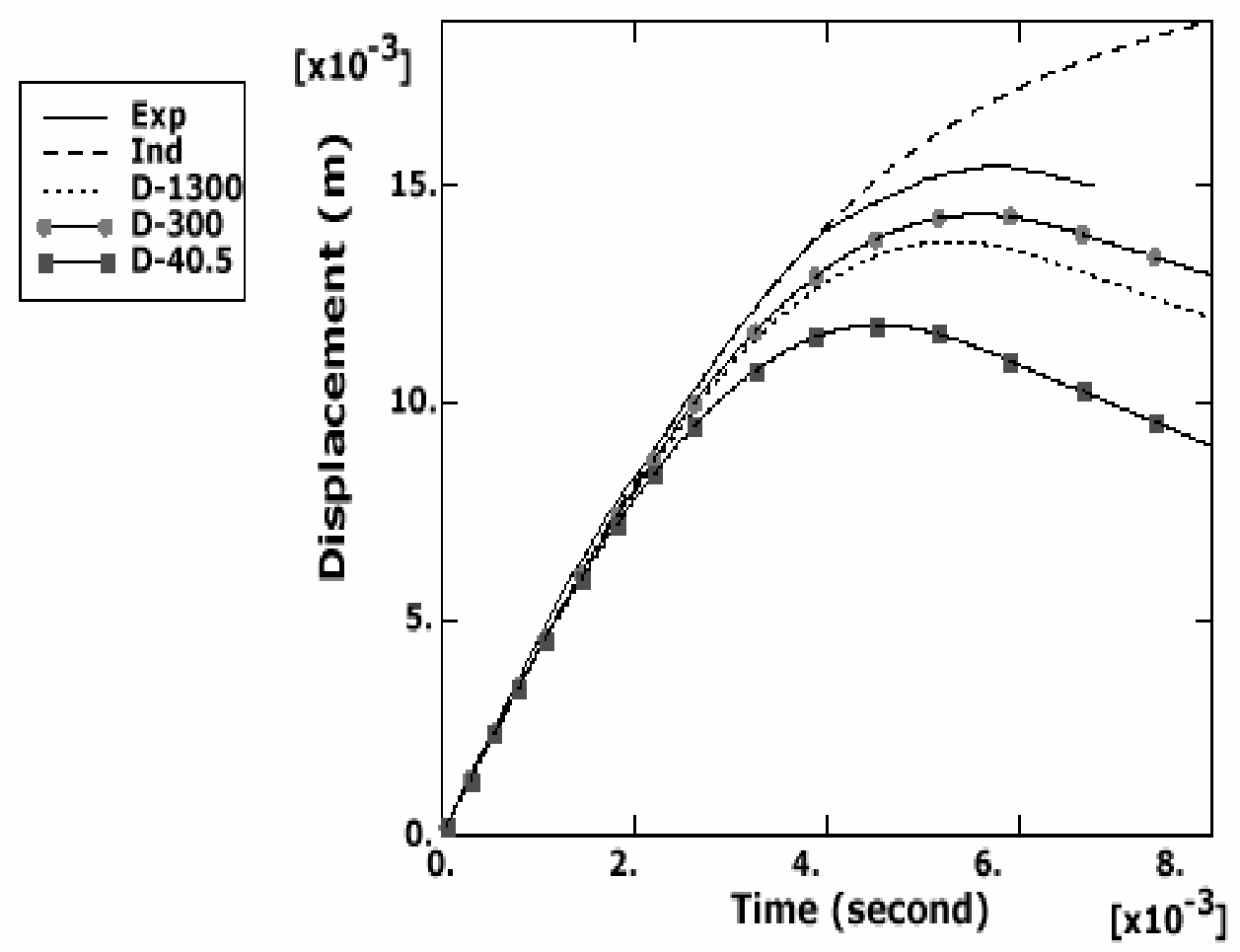

Figure 7. Comparison of the displacement time response of flat-end striker between the experimental (Wen and Jones, 1993) and ABAQUS 2-D model for different values of $D$ and $p$
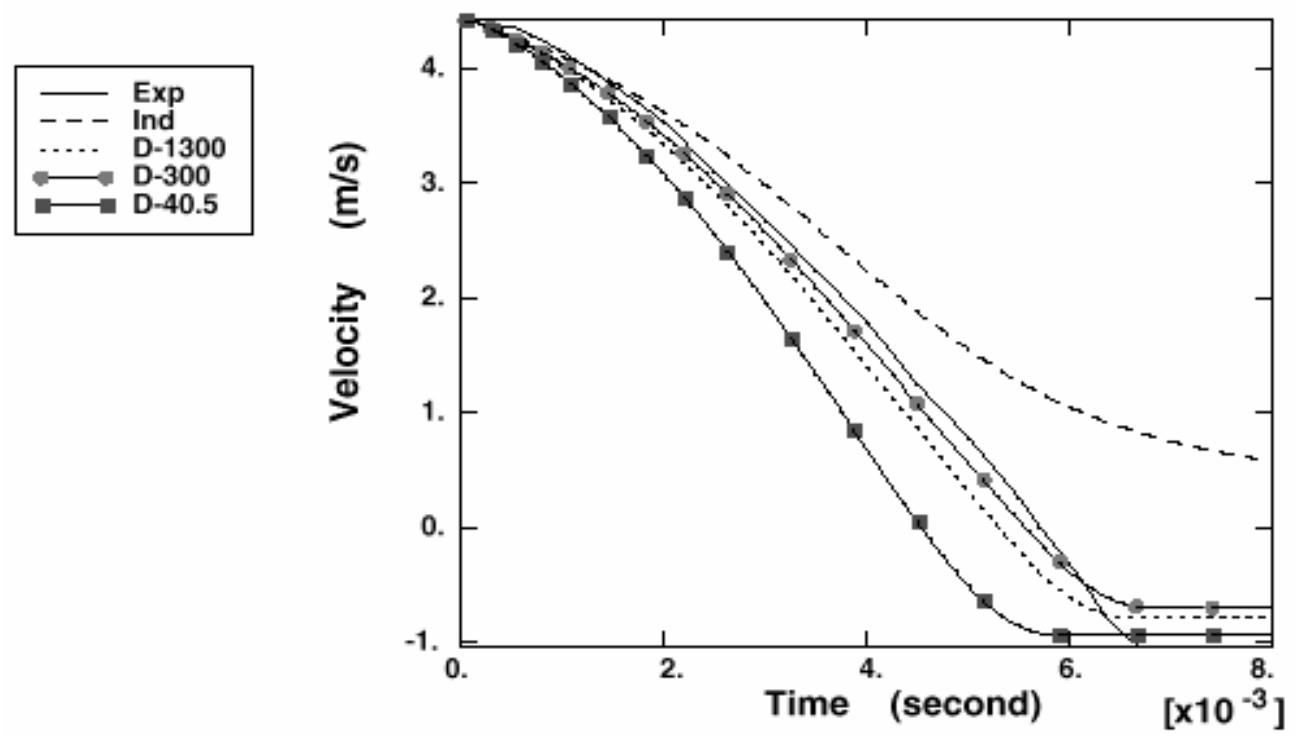

Figure 8. Comparison of velocity v/s time response of flat-end striker between the experimental (Wen and Jones, 1993) and ABAQUS 2-D model for different values of $D$ and $p$

small.

In order to allow the energy to be transferred from striker to the plate, an appropriate contact zone was established between the contacting surfaces. No friction was introduced in the contact zone, and also no failure criterion was incorporated into the solution procedure.

\subsection{Adaptive meshing}

Adaptive meshing is one of the tools that is available in ABAQUS/Explicit Version 5.8. It enables the model to maintain a high quality mesh automatically by allowing the mesh to move independent of the underlying material even when it is subjected to large deformations. With adaptive meshing, node and element numbering and con- 

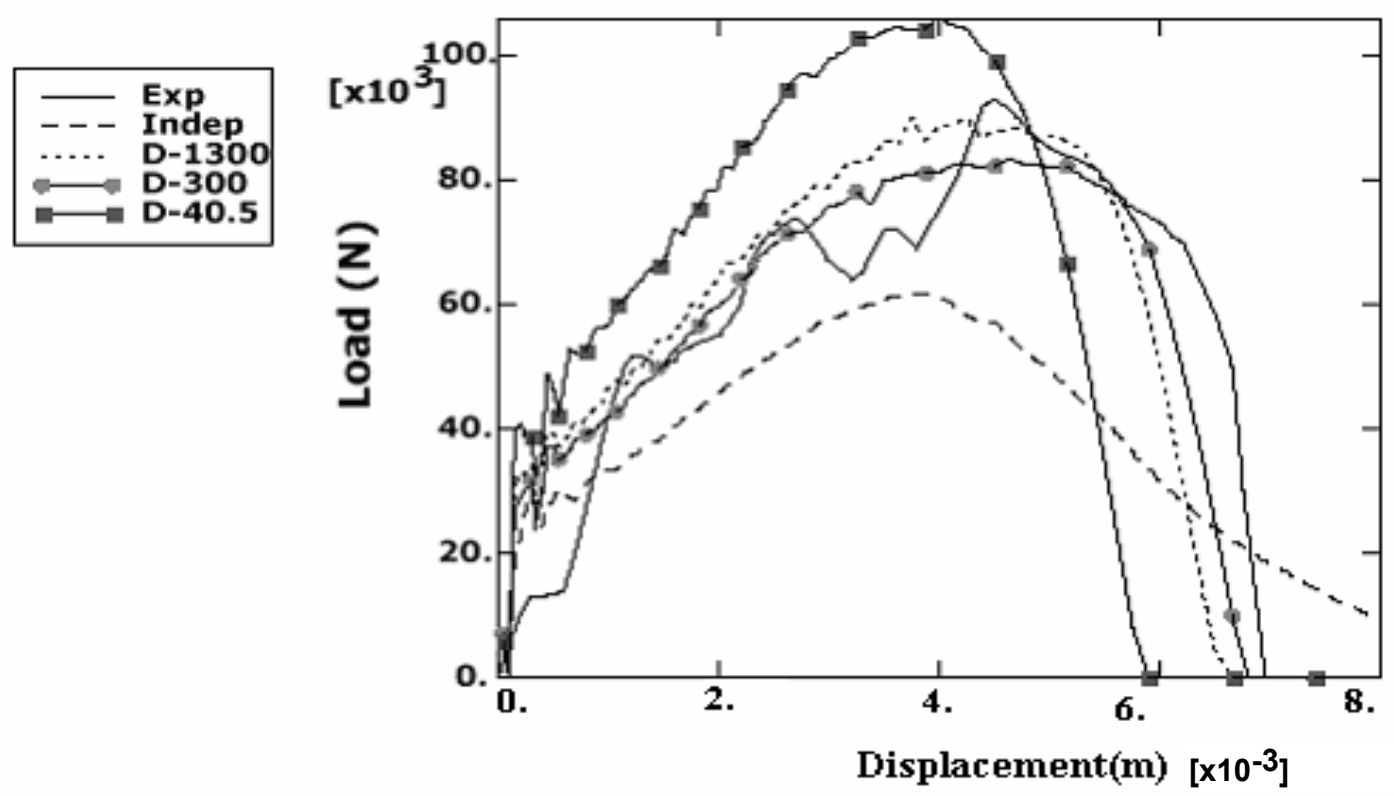

Figure 9. Comparison of load-displacement curves of flat-end curves of flat-end striker between experimental (Wen and Jones, 1993) and ABAQUS 2-D mode for different values of $D$ and $p$

nectivity remain constant throughout the analysis, despite the fact that nodal locations change with respect to the material. However, the same elements adopt to remain well shaped even as the underlying material changes shape. Although adaptive meshing is only available for first-order, reduced-integration continuum elements, it was imposed throughout the 2-D model.

\subsection{Discussion of Results}

The response of the flat-end striker to orthogonal impact with the plate is described in Figure 7 by global deformations, with the possibility of a local failure at the region of impact. The results show the predictions due to the 2-D model, with no strain rate (Ind), as well as the experimentally (Exp) measured values (Wen and Jones, 1993; Wen and Jones, 1994). Figure 8 displays the variation of velocity of the auxiliary node attached to the rigid striker surface with time (Ind) for a striker velocity of $4.43 \mathrm{~m} / \mathrm{s}$. The same figure also displays the experimentally (Exp) measured values (Wen and Jones, 1993; Wen and Jones, 1994). Note that the FEM predictions (Ind) were obtained when strain rate dependence was not included in the analysis. The curves identified by $\mathrm{D}=1300, \mathrm{D}=300$ ( Su et al.,1995) and $\mathrm{D}=40.5$ in Figures 7 and 8 were obtained when strain rate dependence was included in the analysis for $D=1300 \mathrm{~s}^{-1}$ and $p=5, D=300 \mathrm{~s}^{-1}$ and $p=2.5$, and $D=40.5 \mathrm{~s}^{-1}$ and $p=5$, respectively.

With reference to Figure 7, it was observed that the experimentally measured maximum forward displacement of the striker (and hence of the plate) is reached after 5.8 msec. At this time the striker has already ruptured the plate, but it does not have the potential to go through. Thereafter the plate motion is stopped, and then reversed, as may be observed by the falling slope in Figure 7. This reversal may be explained in terms of the stored recoverable strain energy within the plate, causing the plate to oscillate, such that the striker perhaps separates from the plate, and bounces back in the reverse direction.

It is interesting to note that finite element analysis predicts this phenomenon correctly. Thus referring to Figure 7, when strain rate dependence was not included in the analysis (Ind), the striker penetrates and passes through the plate, causing local damages by rupture. It does not rebound. However, when strain rate dependence was considered in the analysis, trends that are similar to the experimental results can be clearly observed. Thus in the case of $D$ - curves in Figure 7 the striker does not penetrate through the plate, signaling that the material is strongly strain rate dependent. This is particularly true for the case when $D=300 \mathrm{~s}^{-1}$ and $p=2.5$. This observation agrees with the study reported in ( Su et al.,1995). More interestingly, lower values of the strain rate constant $D$ tends to lower the contact time of the striker with the plate, indicating that strain hardening properties of the material also influence the development of local plastic deformation, especially during the early stage of deformation.

The phenomenon revealed by Figure 7 can be also witnessed from a study of the velocity-time curve of Figure 8. Experimentally, the velocity of the striker (Exp) is seen to decrease monotonically with time until it becomes zero at time $=5.8 \mathrm{msec}$. The striker then rebounds, and bounces back at a constant velocity of about $1 \mathrm{~m} / \mathrm{s}$. The $D$-curves 
(a)

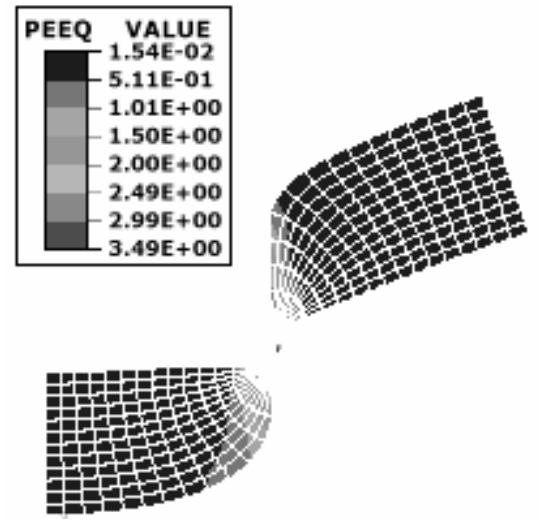

(c)

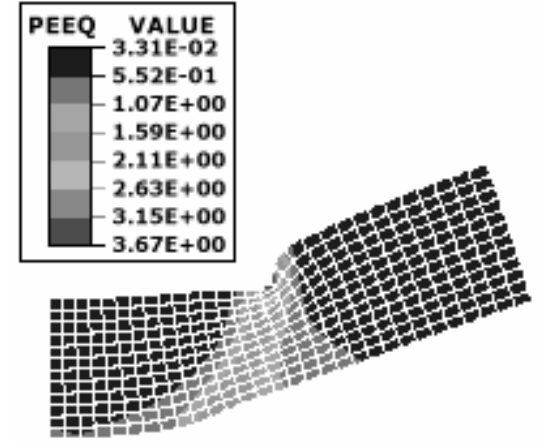

(b)

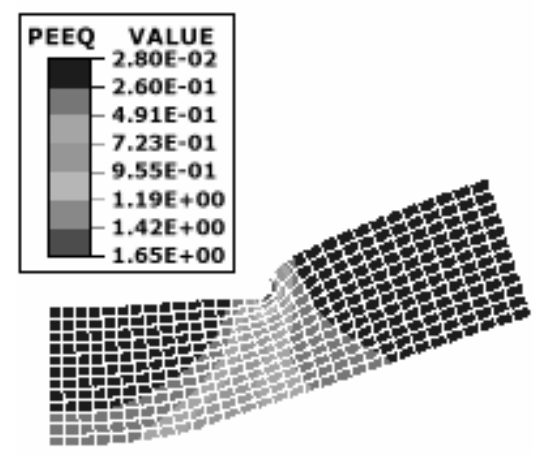

(d)

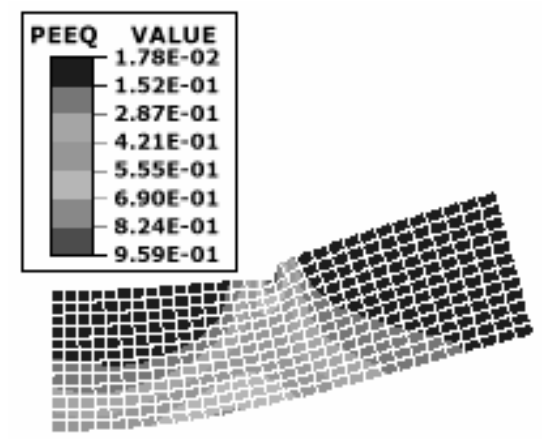

Figure 10. Equivalent plastic strain contour, PEEQ, for elements in vicinity of impacted zone for (a) strain-rate independent, (b) $\mathrm{D}=1300 \mathrm{~s}^{-1}$ and $p=5$, (c) $\mathrm{D}=300 \mathrm{~s}^{-1}$ and $p=2.5$, (d) $\mathrm{D}=$ $40.5 \mathrm{~s}^{-1}$ and $p=5$
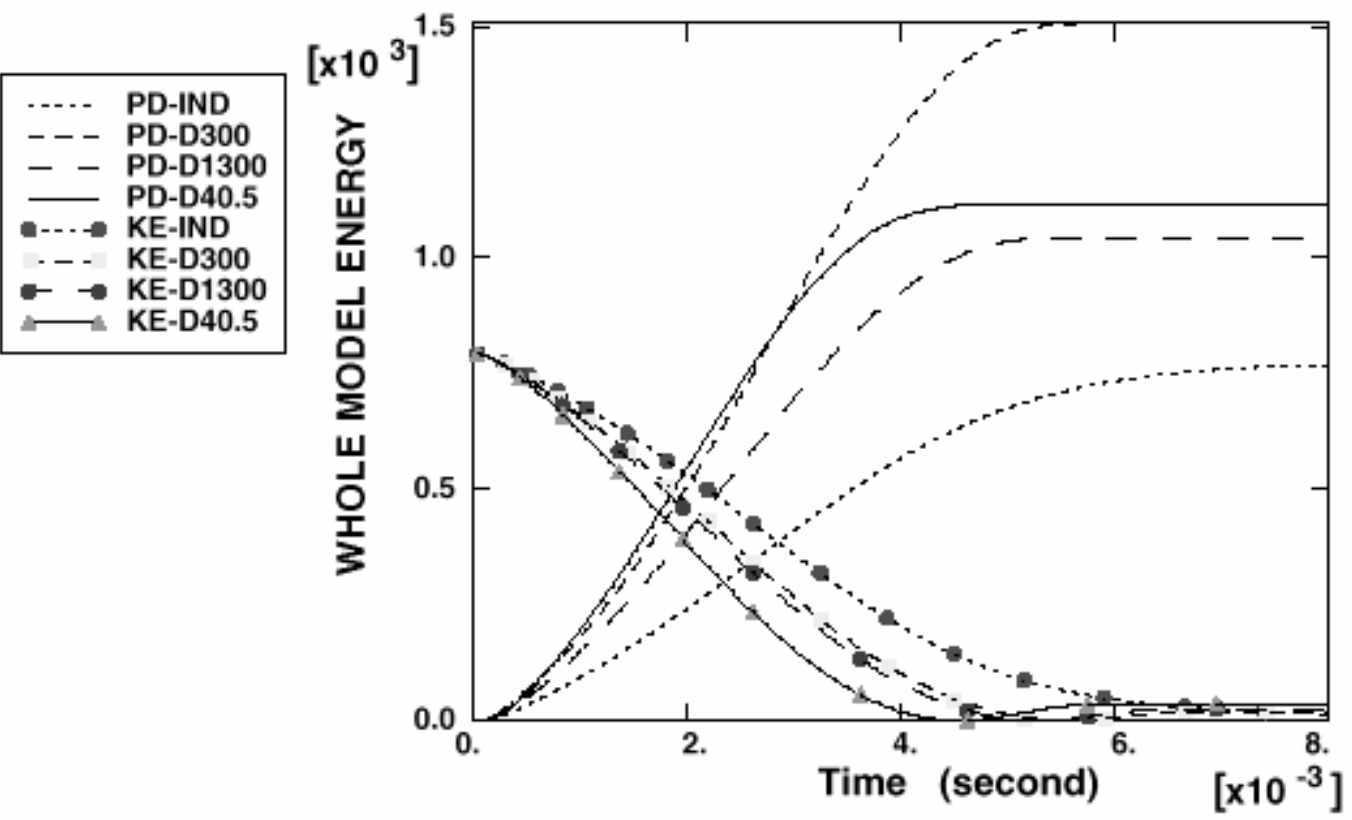

Figure 11. Model kinetic energy curves, KE, and total energy curves due to plastic deformation, $P D$, of flat-end striker for different values of $D$ and $p$ 


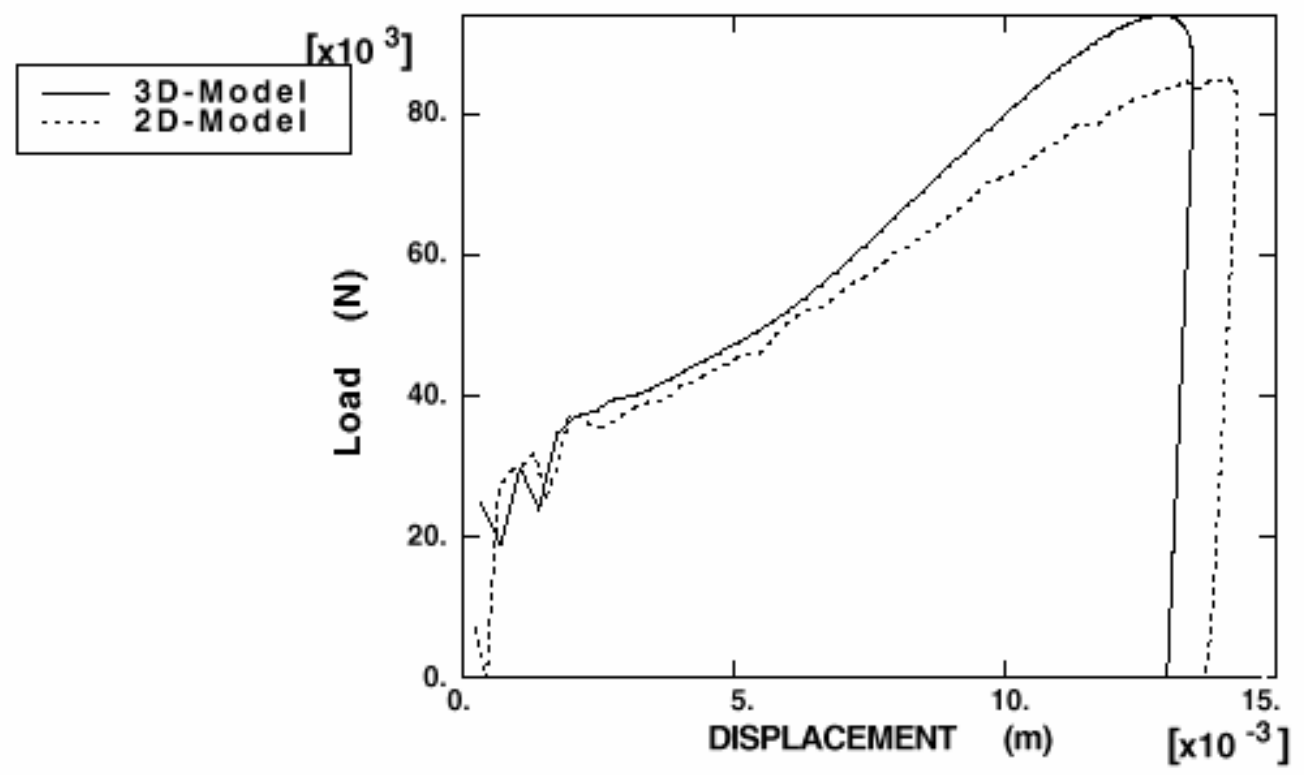

Figure 12. Comparison of load-displacement curves for the flat-end striker, between 2-D and 3-D models, at $v=4.43 \mathrm{~m} / \mathrm{s}$, for $D=300 \mathrm{~s}^{-1}$ and $p=2.5$

(a)

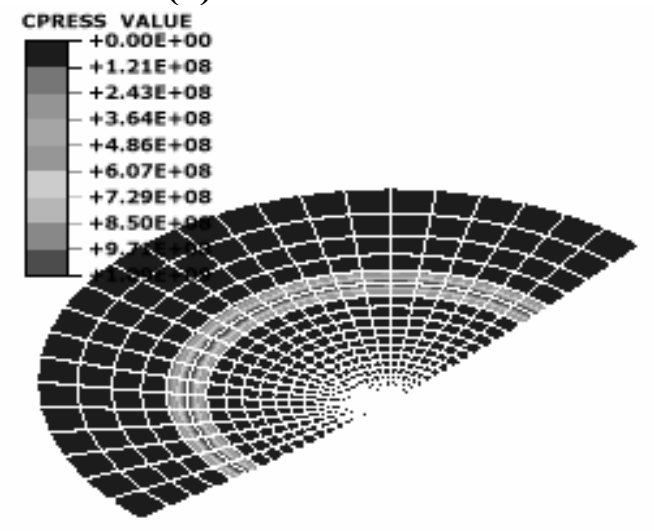

(c)

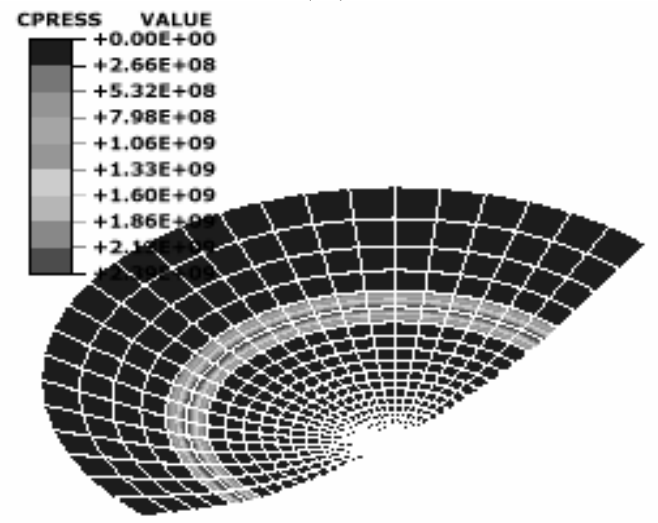

(b)

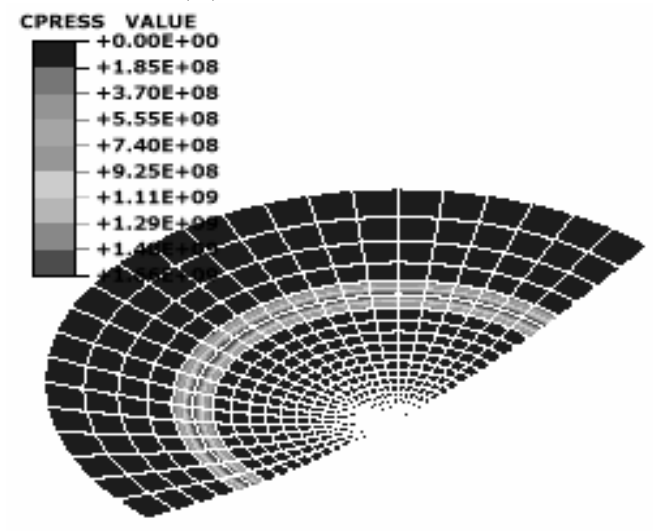

(d)

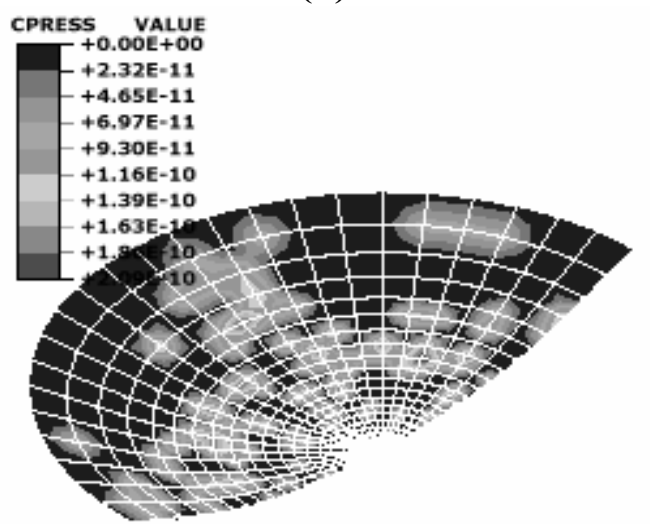

Figure 13. Contact pressure contour at time: 1.04 , (b) 4.16 , (c) 6.16 and (d) $7.28 \mathrm{msec}\left(\mathrm{D}=300 \mathrm{~s}^{-1}\right.$ and $p=2.5)$ 
(a)

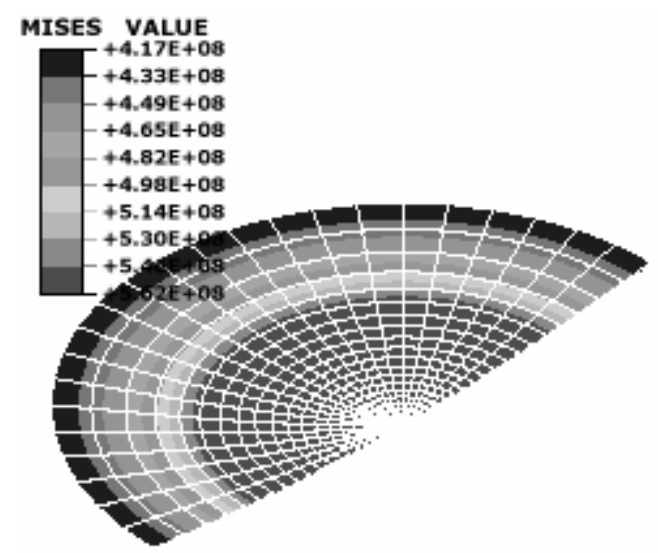

(c)

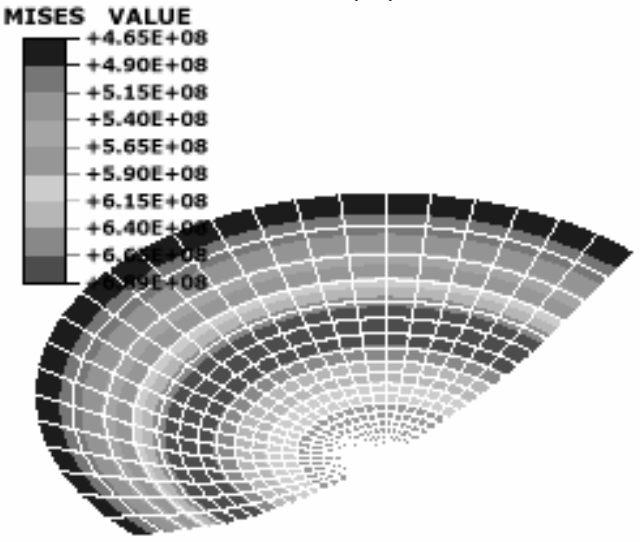

(b)

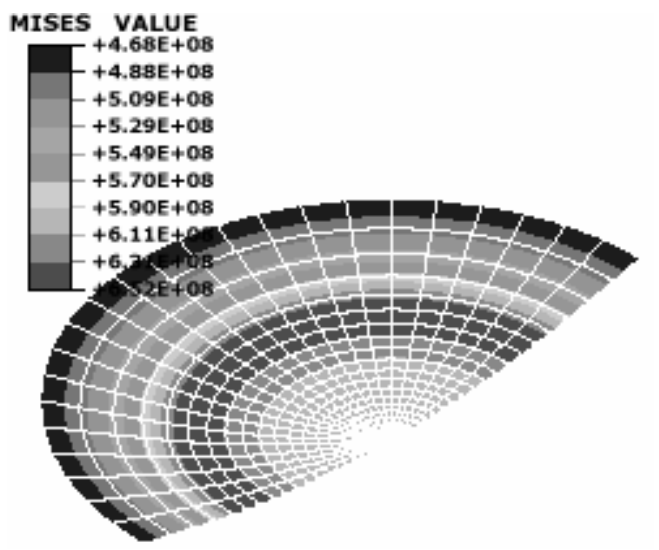

(d)

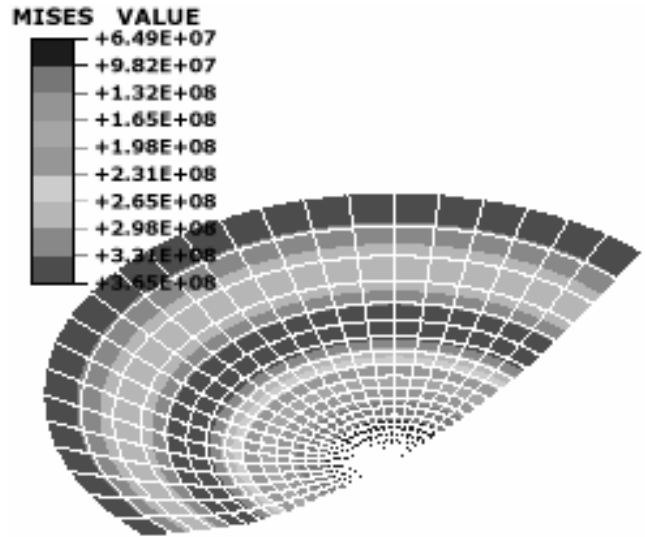

Figure 14. Vos Mises stress contour at time: (a) 1.04, (b) 4.16, (c) 6.16, and (d) 7.28 msec. (D= $300 \mathrm{~s}^{-1}$ and $p=2.5$

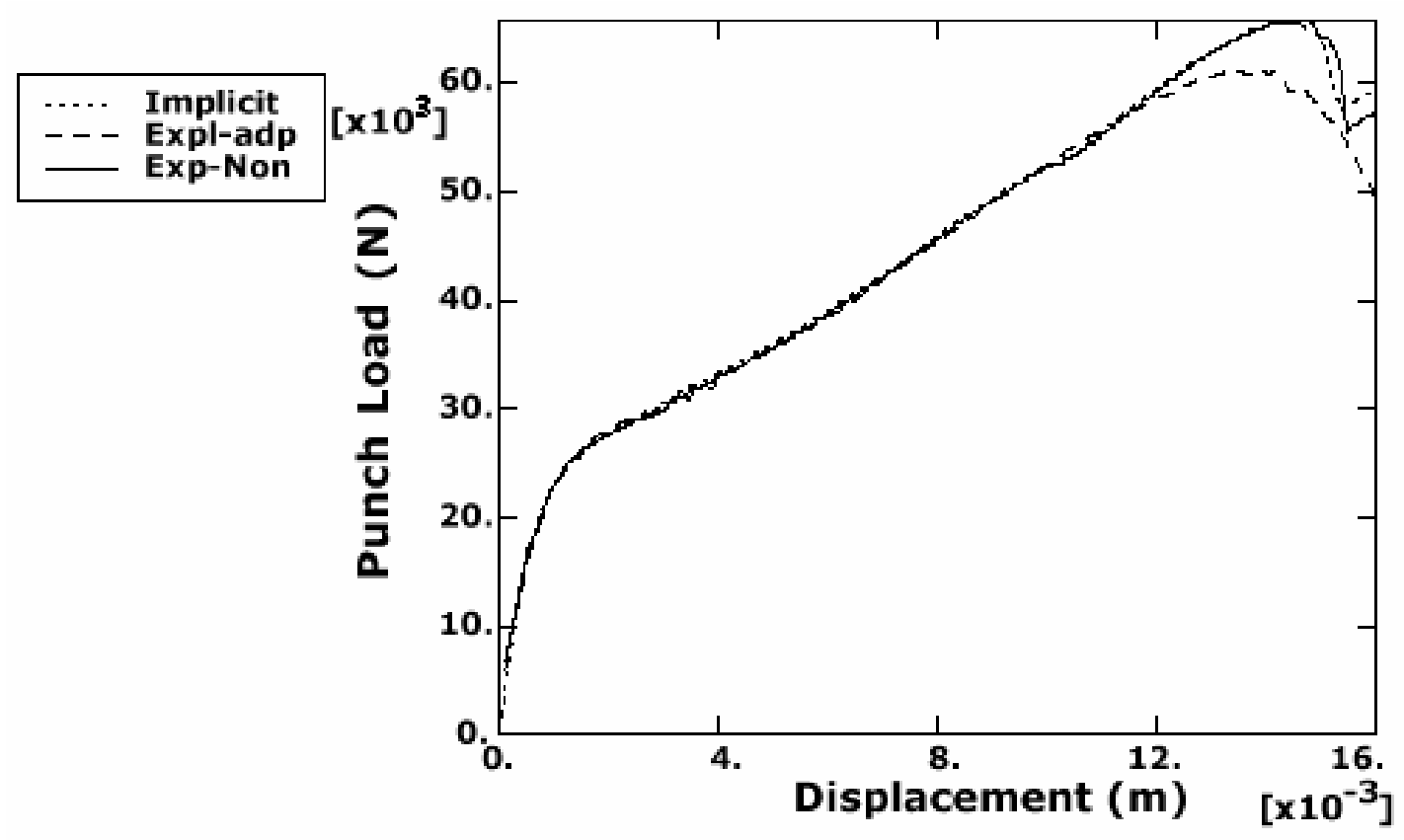

Figure 15. Load-displacement curves for quasi-static case with flat-end striker using implicit and explicit (adaptive and non-adaptive meshing) methods 


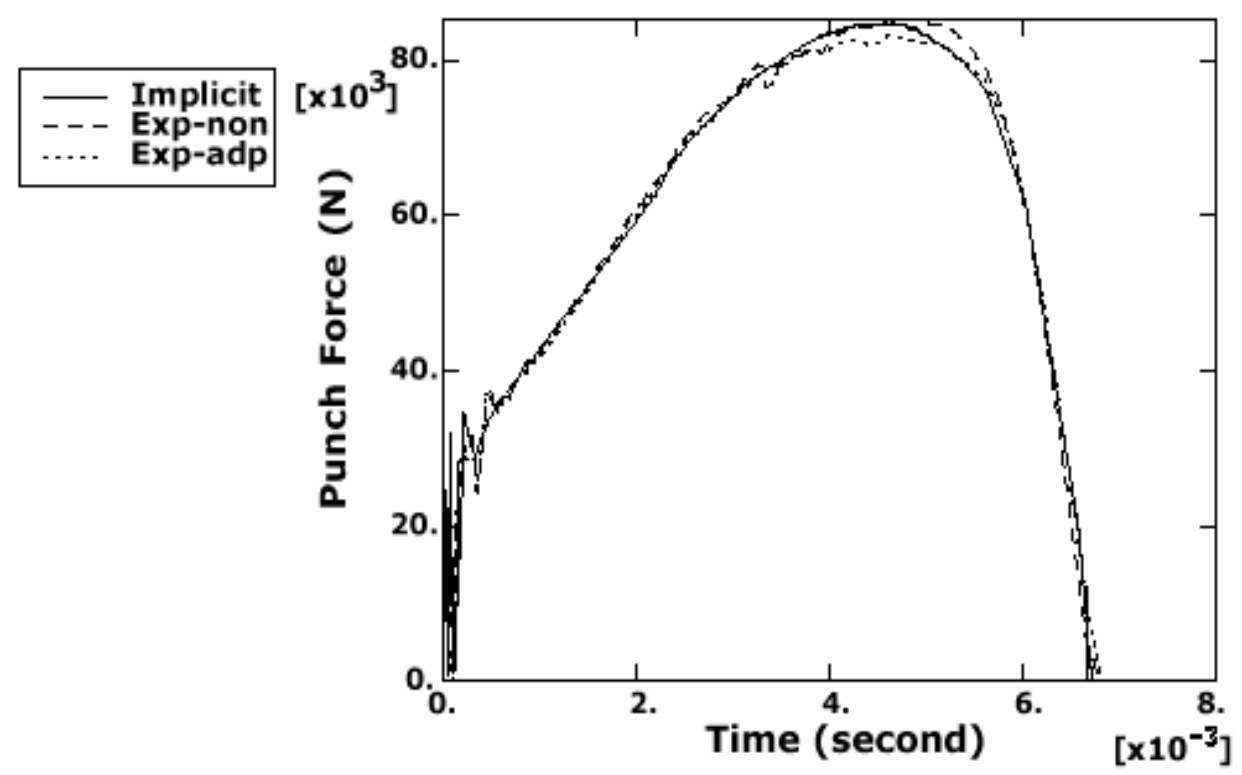

Figure 16. Dynamic load-displacement curves for the flat-end striker, using implicit and explicit (adaptive and non-adaptive meshing) methods, at $\mathrm{v}=4.43 \mathrm{~m} / \mathrm{s}$

in Figure 8 indicate that the striker actually rebounds with a constant velocity when the strain rate effect is taken into consideration. It may be noticed in the same figure that when strain rate is not taken into account (Ind), the striker decelerates upon impact, and then continues to travel in the same direction. This is a clear indication that the striker actually goes through the plate, according to this prediction.

The variation of the striker load with displacement is shown in Figure 9 for the same cases indicated as in Figures 7 and 8 . Here the load is computed as the product of mass times the acceleration of the reference node attached to the rigid surface. Figure 9 shows that, as the striker comes into contact with the plate, strong oscillations are induced in the plate. Furthermore, lower loads were observed when no strain rate was taken into account during the analysis. It is also evident from Figure 9 that, for the case when $D=300 \mathrm{~s}^{-1}$ and $p=2.5$, the FEM analysis results closely matches with the experimental findings. Closer observation in Figure 9 shows that lower values of strain rate hardening modulus $(D)$ tend to increase the load required for deformation, and also tend to decrease the contact time of the striker with the plate.

Figure 10 shows the contours of equivalent plastic strain within the impact zone at time $\mathrm{t}=8.0 \mathrm{msec}$ for the cases treated in Figures 7-9. As it would be expected, with no strain rate effect (a), the striker has actually gone through the plate, and the plate is perforated. Cases (b) to (d) depict the cases with strain rate effects, where all elements, which have equivalent plastic strain greater than one, have been removed. It may be pointed out that cracking may occur in the plate. Plugging of the plate is also possible, especially with $D=300 \mathrm{~s}^{-1}$ and $p=2.5$. Although not shown here, it was found that, with $D=300 \mathrm{~s}^{-1}$ and $p=2.5$, a small increase in the initial speed to $4.98 \mathrm{~m} / \mathrm{s}$ tended to increase the punch load as well as the contact time, and consequently causing more energy to be dissipated due to plastic deformation.

The time variation in kinetic energy (KE), and energy dissipated due to plastic deformation (PD), are shown in Figure 11 for the cases of strain-rate dependent ( $D$-curves) and strain-rate independent (Ind) materials. As expected, all of the curves indicated that, as kinetic energy decreases with time, most of the energy is being transferred to the plate, and consumed for rupturing and plastic work dissipation. Then kinetic energy tends to increase where considerably less energy is available for the striker. Furthermore, with strain rate effect, more energy is dissi-

pated due to plastic deformation for $D=300 \mathrm{~s}^{-1}$ and $p=2.5$ than for other values. This is the case in which the contact time of the striker with the plate is longer than for $D=1300 \mathrm{~s}^{-1}$ and $p=5$, and for $D=40.5 \mathrm{~s}^{-1}$ and $p=5$.

Figure 12 shows comparisons of load-displacement curves between the 2-D and 3-D models, using the explicit method. Note that adaptive meshing was not included in the analysis since it is not available for shell elements. Both models were observed to yield similar trends. The $3-$ $\mathrm{D}$ model however, depicted a higher peak load and lower contact time than the 2-D model.

It must be emphasized here that the 2-D model is rather limited in the amount of insight it provides. The 3-D model was therefore utilized in an effort to acquire more precise information regarding changes on the surface of the plate due to impact loading within the impact zone; 


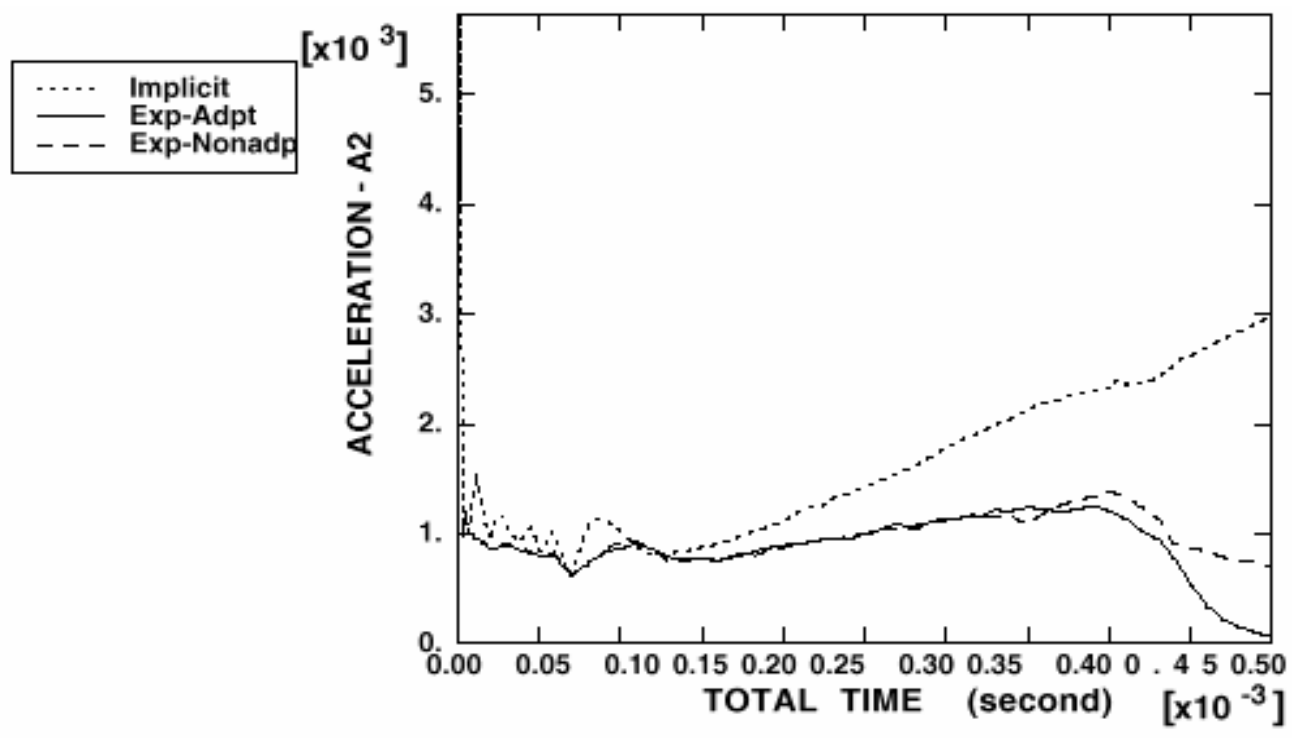

Figure 17. Comparison of the acceleration time responses of flat-end striker, using implicit and explicit (adaptive and non-adaptive meshing) methods, at $\mathrm{v}=\mathbf{5 0 . 0} \mathrm{m} / \mathrm{s}$

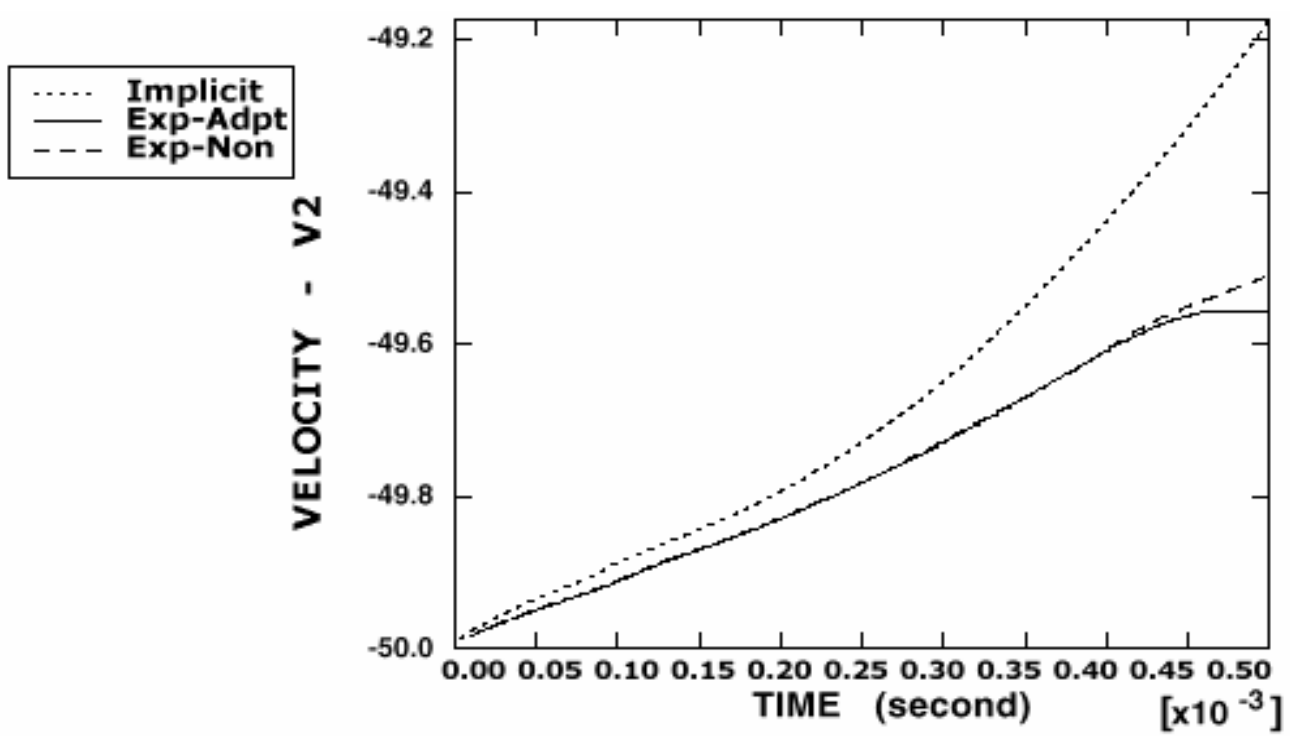

Figure 18. Comparison of the velocity time responses of flat-end strike, using implicit and explicit (adaptive and non-adaptive meshing) methods, at $\mathrm{v}=\mathbf{5 0 . 0} \mathrm{m} / \mathrm{s}$

contours of the contact pressure. The results presented in Figure 13 for four different stages of impact, i.e., at the time when the load at the beginning of its monotonic increase, at its peak, at the instant when it becomes zero, and during the rebound.

Inspection of Figure 13 shows that the contour profiles do exhibit the symmetry of the plate. It can be observed that, during the impact, the contours of the constant pressure between the striker and the plate is localized, and that they are concentrated in the vicinity of the outer radius of the striker. The contact pressure disappears, however, dur- ing the period of rebound. Contours of the Von-Mises equivalent stresses shown in Figure 14 indicate that the growth of the plastic zone commences from the right side to the vicinity of the impact, and grows gradually outward in a monotonic fashion.

\section{Explicit Versus Implicit}

Since it is possible to study quasi-static nonlinear problems as well as linear dynamic problems by the use of both the implicit and the explicit versions of ABAQUS (Su et 
al., 2000; HKS, 1994), it would be of interest to compare the results of the two. Furthermore the comparisons can be extended to quasi-static and dynamic nonlinear problems in which adaptive meshing can be taken into consideration.

Normally the explicit method is limited to short transient problems. In order to be able to run the explicit method for quasi-static problems, it would be necessary to make the inertia effect negligibly small by allowing the striker to move at a very low constant speed. Below both the explicit and the implicit methods were used for the analysis of clamped circular plate of section 3 loaded by a flat-end striker.

For the quasi-static case, and using the explicit method (with and without adaptive meshing), the striker was allowed to move at a uniform speed of $0.05 \mathrm{~mm} / \mathrm{s}$ while it traveled a distance of $16 \mathrm{~mm}$. A fixed mass scale factor of 50 was used in order to increase the computational speed of explicit analysis. Using the implicit method however, no speed controls were applied on the striker while traversing the same distance. It took only $177.19 \mathrm{~s}$ of CPU time for the implicit solution, while it required $3 \mathrm{~h}, 13 \mathrm{~min}$, and $26 \mathrm{~s}$ of CPU time for the explicit non-adaptive, and 3 h, $18 \mathrm{~min}$, and $4 \mathrm{~s}$ of CPU time for the explicit method with adaptive meshing. It was found that CPU time is inversely related to striker velocity for computation by the explicit version, whereas CPU time for the implicit solution is not affected by striker velocity.

Figure 15 displays the load-displacement curves for quasi-static loading using the implicit and explicit (with adaptive and non-adaptive meshing) methods. There seems to be good agreement between the implicit and the explicit non-adaptive meshing solutions. The large discrepancy of explicit solution with adaptive meshing can clearly be observed for higher loads, that is, when plastic deformation on the plate becomes severe, especially in the vicinity of the edge of the striker. Adaptive meshing does not seem to adopt itself to large deformation effects on the mesh. Although not shown here, similar large discrepancies were observed for adaptive meshing when comparing stresses and strain contours in the vicinity of the striker edge.

Figure 16 shows the variation of load-displacement curves obtained by the implicit and explicit (with adaptive and non-adaptive meshing) methods when the striker was given an initial velocity of $4.43 \mathrm{~m} / \mathrm{s}$ and a transient period of $8.0 \mathrm{~s}$. It may be verified from Figure 16 that the implicit method results in more oscillations than those obtained using the explicit method at the beginning of impact. It took $1041.2 \mathrm{~s}$ of CPU time for the implicit method, using a HAFTOL (Half Tolerance) value of 120000 (higher than the reaction force). For more accurate results, a decrease in HAFTOL, to a value of $10 \%$ of the reaction force, would significantly increase the CPU time. Nevertheless, the CPU time of the implicit solution is still small when compared to $2228 \mathrm{~s}$ and $2142 \mathrm{~s}$ required by the explicit method, with and without adaptive meshing, respectively.
Increasing the initial striker velocity to $50 \mathrm{~m} / \mathrm{s}$ and considering a transient period of $0.5 \mathrm{~s}$, results in a CPU time of $580 \mathrm{~s}$ for the implicit method using a HAFTOL value of 120000 , while for the explicit method it takes $381 \mathrm{~s}$ and $240 \mathrm{~s}$, with and without adaptive meshing, respectively. Variations of striker acceleration and of velocity with time for this case are displayed in Figures 17 and 18, respectively. It may be verified from these figures that, according to the implicit analysis, the striker remains in contact with the plate, while it passes through the plate according to the explicit analysis.

In summary, the implicit method seems to be best suited for quasi-static and slow contact problems. The explicit method excels in the speedy analysis of impact problems with high speed and low transient periods. The latter method has the added capability to utilize adaptive meshing and the possibility to incorporate a failure criterion.

\section{Conclusions}

Standard implicit and explicit versions of the ABAQUS (Ver.5.8) code were used to investigate the behavior of simply supported and clamped circular plates when subjected to centric orthogonal impact loadings. Strikers having hemispherical-end and flat-end rigid cylinders induced the loadings. One case reported here dealt with quasi-static loadings. Dynamic loadings involved a relatively high striker mass, and a number of low impact striker velocities. Material properties that were utilized in the FEM modeling of the plate were obtained from experiments conducted under dynamic load conditions. Material properties were linear in the elastic range, and exhibited nonlinear isotropic work-hardening characteristics in the plastic regime. They were strain dependent. The agreement between the experimental and computed values was note worthy. The implicit methods gave better results for quasistatic and slow contact problems.

\section{Acknowledgments}

The author would like to express his appreciation to Professor M. Akyurt for his useful comments and help during the preparation of this manuscript.

\section{References}

Aljawi, A. A., 1999, "Penetration and Failure of Thin Plates Subjected to Impact Loading," Third International Conf. on Shock \& Impact Loads on Structures 99", 24-26 November, 42-50, 1999, Singapore.

Awerbush, J., and Bonder, S. R., 1974, "Analysis of the Mechanics of Perforation of Projectiles in Metallic Plates," Int. J. Solid Structures. Vol. 10, 671-684.

Bammann, D. J., Chjiesa, M. L., Horstemeeyer, M. F., and 
Weigaten, L. T, 1993æ "Failure in Ductile Materials Using Finite Element Methods, Structural Crashworthiness and Failure", Ed N. Jones, and Wierzbick, Elsevier Applied Science, London and New York, 1-54.

Beckman, M. E., and Goldsmith, W., 1978, "The Mechanics of Penetration of Projectiles into Targets," Int. J. Engng. Sci, Vol. 16, 1-99.

Corbett, G. G., and Reid, S. R.,1993, "Quasi-Static and Dynamic Local Loading of Monolithic SimplySupported Steel Plate," Int. J. Impact. Engng. Vol. 13, No. 3. pp. 423-441.

Corbett, G. G., Reid, S. R., and Johnson, W., 1997, "Impact Loading of Plates and Shells by Free-Flying Projectiles: a Review," Int. J. Impact Engng, Vol. 18, No. 2, 141230.

Corran, R. S. J., Shadbolt, P. J., and Ruiz, C., 1993, "Impact Loading of Plates an Experimental Investigation," Int. Impact Engng, Vol. 1, No. 1, 3-22.

Davies, G. A. O., 1984a, "Structural Impact and Crashworthiness," Volume 1, Elsevier Applied Science Publishers, London and New York.

Davies, G. A. O., 1984b, "Structural Impact and Crashworthiness," Volume 2, Elsevier Applied Science Publishers, London and New York.

Goldsmith, W., 1972, "Impacts," Edward Arnold, London.

HKS, Inc., 1994, "Application of Implicit and Explicit Finite Element Techniques to Metal Forming," J. Mater. Process. Techno., 45, pp. 649-656.

HKS, Inc, 1998, “ABAQUS/Explicit User's Manual, Theory and examples manuals and Post Manual, Version 5.8, Explicit,".

Jones, N., 1989, "Structural Impact," Cambridge University Press.

Jones. N, 1983, "Structural Aspect of Ship collisions," In Structural Crashworthiness, Chapter 11, pp. 308-337 (Edited by N. Jones and wierzbicki). Butterworth.

Jones. N., Birch., S,E., Birch., C, S., Xhu, L., and Brown, M., 1992, "An Experimental Study on the Lateral Impact of Fully Clamped Mild Pipes," Proc. Inst. Mech. Engrs., Vol. 206 (E), 111-127.

Jones, N., and Shen, W. Q., 1993, "Criteria for the Inelastic Rupture of Ductile Metal Beams Subjected to Large Dynamic Load," Structural Crashworthiness and failure, Ed. N Jones and T. Wierzbicki, Elsevier Applied Science Publishers, London and New York, 95-130.

Kormi, K., Shaghoueie., and Duddell, D.A., 1994, “Finite
Element Examination of Dynamic Response of Clamped Beam Grillages Impacted Transversely at their Center by a Rigid mass," Int. J., Impact Engng, Vol. 15, No. 5, 687-697.

Kormi, K., Webb, D. C., and Etheridge, R. A.E., 1993, "The Use of FEM to Evaluate the Response of Damaged Pipes- Part 1-Static Loading ', PVP-Vol. 264, Piping, Support and Structural Dynamics, 147-158, ASME.

Kormi, K., and Webb, D. C., 1993, "The Use of FEM to Evaluate the Response of Damaged Pipes- Part 2Dynamic Loading ', PVP-Vol. 264, Piping, Support and Structural Dynamics, 159-167, ASME.

Langsen, M., and Larson, P. K., 1990, "Dropped Object Plugging Capacity of Steel Plates: an Experimental Investigation,' Int. J. Impact Engng, Vol. 9, No. 3, 289316.

Reid, S. R., 1985, "Metal Forming and Impact mechanics," Pergamon Press Ltd.

Shen, W. Q., and Jones, N., 1993,"Dynamic response of a Grillage Under Mass Impact,” Int. J. Impact Engng, Vol. 123, 555-565.

Su, X. Y., Yu, T. X., and Reid, S. R., 1995, "InertiaSensitivity Impact Energy-Absorbing Structures. Part II: Effect of Strain Rate,” Int. J. Impact. Engng, Vol. 16, No. 4, pp. 673-689.

Sun, J. S., Lee, K. H., and Lee, H.P., 2000, “ Comparison of Implicit and Explicit finite Element Methods for Dynamic Problems," J. Mater. Process. Technology, 105, pp. 110-118.

Symonds, P. S., 1965, "Viscoplastic Behavior in response of Structures to Dynamic Loading," Behavior of Materials Under Dynamic Loading (Ed by N. J., Huffington), 106-124, SME, New York.

Wen, H.M, and Jones, N., 1993, "Experimental Investigation of the Scaling Laws for Metal Plates Struck by Large Masses," Int. J. Impact. Engng, Vol. 13, No. 3, pp. 485-505.

Wen, H. M., and Jones, N., 1994, "Experimental Investigation into the Dynamic plastic response and Perforation of a clamped Circular Plate Struck Transversely by a Mass," Proc. Ints. Mech. Engrs, I. Mech. E., Vol. 208, 113-137.

Zhao, X. L., and Grzebieta, 2000, "Structural Failure and Plasticity," Proceedings of the $7^{\text {th }}$ Int. Sym. On Structual Failure and Plasticity, IMPLAST 2000, Pergamon. 
The Journal of Engineering Research 1 (2004) 59-73 